STUDI DISKRIPTIF KUALITATIF:

\title{
PERAN TIM SIAGA BENCANA BERBASIS MASYARAKAT (SIBAT) MENJARING PENYINTAS COVID-19 UNTUK DONOR PLASMA KONVALESEN DI KOTA SURAKARTA
}

\author{
Syarifah $^{1}$; Barli Shodiq ${ }^{2}$ \\ ${ }^{1}$ Diploma Tiga Teknologi Bank Darah, Politeknik AKBARA Surakarta; ${ }^{2} \mathrm{PMI}$ \\ Kota Surakarta \\ syarifah@akbara.ac.id; barlyshodiq26@gmail.com
}

\begin{abstract}
ABSTRAK
Pendahuluan. Rendahnya minat pendonor plasma konvalesen menyebabkan terapi ini masih sangat kurang untuk memenuhi kebutuhan pasien positif COVID19. Jumlah penderita yang tinggi namun pendonor plasma konvalesen yang rendah menyebabkan angka kesembuhan yang belum dapat dimaksimalkan. Untuk itu Palang Merah Indonesia menggalakkan peran aktif relawan Tim SIBAT. Tim SIBAT sebagai Satuan Tugas Jogo Tonggo untuk memberikan informasi dan mengajak penyintas COVID-19 untuk melakukan donor plasma konvalesen. Tujuan. Untuk mengetahui peran Tim SIBAT dalam penanganan COVID-19 serta kendala dalam menjaring penyintas COVID-19 untuk melakukan donor darah plasma konvalesen. Metode. Metode penelitian yaitu studi kualitatif dengan wawancara tim SIBAT PMI Kota Surakarta sebanyak 8 orang untuk mengetahui faktor penyebab rendahnya minat donor plasma konvalesen pada penyintas COVID-19. Hasil. Peran dari Tim SIBAT untuk menjadi Satgas Jogo Tonggo. Faktor yang mempengaruhi dalam menjaring penyintas COVID-19 yaitu kurangnya pengetahuan tim SIBAT mengenai teknis donor plasma konvalesen, stigma penderita COVID-19 yang masih tinggi di masyarakat serta ketidak tahuan penyintas COVID-19 mengenai manfaat dari donor plasma konvalesen. Simpulan. Perlu dilakukan pelatihan lanjutan bagi Tim SIBAT, sosialisasi kepada masyarakat mengenai manfaat donor plasma konvalesen, koordinasi dengan pemerintah dan dinas terkait untuk melakukan pencanangan donor plasma konvalesen untuk penyintas COVID-19 serta wadah secara online berupa grup WA, aplikasi khusus penyintas COVID-19 maupun website bagi penggerak donor plasma konvalesen.
\end{abstract}

Kata kunci : Tim SIBAT, COVID-19, Plasma Konvalesen, Donor

\section{ABSTRACT}

Introduction. The low interest of convalescent plasma donors causes this therapy is still very lacking to meet the needs of COVID-19 positive patients. The high number of sufferers but low convalescent plasma donors cause a cure rate that has not been maximized. Therefore, the Indonesian Red Cross encourages the active role of SIBAT Team volunteers. SIBAT team as Jogo Tonggo Task Force to 
provide information and invite COVID-19 survivors to conduct convalescent plasma donors. Objective. To find out the role of SIBAT Team in handling COVID-19 as well as obstacles in attracting COVID-19 survivors to donate convalescent plasma blood. Method. Research method is qualitative study with sibat pmi team interview surakarta as many as 8 people then taken conclusions to find out the factors that cause low interest of convalescent plasma donors in COVID-19 survivors. Result. The role of sibat team to become Task Force Jogo Tonggo. Factors that influence the capture of COVID-19 survivors are the SIBAT team's lack of knowledge about the technicality of convalescent plasma donors, the stigma of COVID-19 sufferers that is still high in the community and the lack of knowledge of COVID-19 survivors regarding the benefits of convalescent plasma donors. Conclusion. Further training is needed for SIBAT Team, socialization to the community about the benefits of convalescent plasma donors, coordination with the government and related agencies to conduct the announcement of convalescent plasma donors for COVID-19 survivors as well as online containers in the form of WA groups, special applications for COVID-19 survivors and websites for convalescent plasma donor drivers.

Key words : SIBAT Team, COVID-19, Convalescent Plasma, Donors

\section{PENDAHULUAN}

Pandemi penyakit Coronavirus 2019 (COVID-19) yang disebabkan oleh SARS-CoV-2 telah mengalihkan seluruh pandangan dunia. Pada bulan Juni tahun 2020 kasus telah menyebar lebih dari 200 negara dan teritori. Amerika menduduki tingkat tertinggi kasus terkonfirmasi berjumlah 4.437.946 dan kasus kematian berjumlah 119.761. Sampai saat ini tidak terdapat obat spesifik ataupun vaksin teruji klinis yang tersedia untuk menangani COVID-19.(Zetira, 2020).

Seperti yang kita ketahui bahwa COVID-19 telah berjalan lebih dari 12 bulan, namun hingga saat ini belum terdapat perbaikan yang signifikan baik di Indonesia mengenai penurunan angka kesakitan, angka kematian maupun kesembuhan dari penderita Covid-19. Berdasarkan data dari www.covid19.go.id pada bulan Desember 2020, angka terkonfirmasi positif COVID-19 di Indonesia sebesar 713.365 orang dengan angka kematian sebesar 21.237 orang.(Gugus Tugas Percepatan Penanganan COVID-19, 2020b).

Angka kejadian tertinggi yaitu DKI Jakarta, Jawa Barat, Jawa Tengah, Jawa Timur, Sulawesi Selatan dan Kalimantan Timur.(Gugus Tugas Percepatan Penanganan COVID-19, 2020b). Solusi dalam mengatasi tingginya angka kematian pada penderita COVID-19 yaitu dengan pemberian donor plasma konvalesen. Banyak negara telah menerapkan terapi plasma konvalesen dan hasil 
dirasakan cukup efektif, namun keberhasilan terapi masih terbatas. Food and Drug Administration (FDA) memberikan rekomendasi terapi pasien COVID-19 menggunakan plasma konvalesen yang diambil dari pasien yang sudah pulih dari infeksi. Beberapa penelitian telah melaporkan bahwa penggunaan plasma konvalesen meningkatkan kelangsungan hidup pasien, memperbaiki gejala klinis, menurunkan angka kematian dan belum ada efek samping yang merugikan secara signifikan. (Zetira, 2020).

Rendahnya minat pendonor plasma konvalesen menyebabkan terapi ini masih sangat kurang untuk memenuhi kebutuhan pasien positif COVID-19. Jumlah penderita yang tinggi namun pendonor plasma konvalesen yang rendah menyebabkan angka kesembuhan yang belum dapat dimaksimalkan.

Untuk itu Palang Merah Indonesia menggalakkan peran aktif relawan berbasis masyarakat yang disebut dengan Siaga Bencana Berbasis Masyarakat (SIBAT). Tim SIBAT memiliki fungsi sebagai Satuan Tugas Jogo Tonggo di wilayahnya masing-masing. Satuan Tugas Jogo Tonggo lebih sering disebut sebagai Satgas Jogo Tonggo, berdasarkan instruksi gubernur provinsi Jawa Tengah menjelaskan bahwa tugas dari satgas Jogo Tonggo adalah untuk mendorong, memastikan dan memantau terselenggaranya protokol kesehatan melawan Covid-19 dengan benar dan efektif di wilayah RW. (Gubernur Provinsi Jawa Tengah, 2020).

Selain itu Tim SIBAT dapat memberikan informasi pencegahan COVID-19 baik mengenai cuci tangan, jaga jarak aman, diam di rumah atau bermasker saat di luar maupun mengajak penyintas COVID-19 untuk melakukan donor plasma konvalesen. (Paraswati, 2020).

Masih rendahnya pendonor plasma konvalesen dari penyintas COVID-19 membuat peneliti ingin mengetahui lebih lanjut kendala-kendala yang ada di lapangan oleh Tim SIBAT dalam menjaring maupun mengajak masyarakat penyintas COVID-19 untuk mengikuti donor plasma konvalesen. Faktor maupun permasalahan yang dihadapi dapat mendapatkan solusi dengan melakukan komunikasi dengan Tim SIBAT. 


\section{METODE}

Penelitian ini menggunakan pendekatan studi deskriptif kualitatif. Pendekatan ini dilakukan dengan memunculkan persoalan $5 \mathrm{~W} 1 \mathrm{H}$ yaitu apa, mengapa, kapan dimana dan bagaimana. Kemudian didapatkan data yang dapat ditarik kesimpulan alasan atau faktor yang mempengaruhi terjadinya hal tersebut. (Arikunto, 2013).

Penelitian ini merupakan penelitian deskriptif yang dalam proses penelitiannya berusaha mendeskripsikan suatu gejala, fenomena atau kenyataan sosial yang berkenaan dengan masalah dan unit yang diteliti. Dalam penelitian yang dilakukan, peneliti melakukan wawancara cara penulis membuat pedoman wawancara, kemudian peneliti melakukan wawancara dengan partisipan yang ada.

Metode penelitian yang dilakukan yaitu studi kualitatif dengan cara melakukan wawancara kepada ada tim SIBAT yang berada di wilayah Kota Surakarta sebanyak 8 orang yang terdiri dari 5 orang ketua Tim SIBAT dari setiap kecamatan dan 3 orang yang aktif dalam pelatihan di PMI Kota Surakarta. Kemudian diambil kesimpulan untuk mengetahui faktor yang menyebabkan rendahnya minat donor plasma konvalesen pada penyintas COVID-19.

Pengambilan sampel secara purposive sampling yaitu teknik pengambilan sumber data dimana sudah ditentukan kriteria (Sugiyono, 2016). Analisa data dalam penelitian ini menggunakan content analysis yaitu analisis berdasarkan isi wawancara yang dikategorikan menurut tema yang muncul (Lexy J. Moleong, 2019)

\section{HASIL DAN PEMBAHASAN}

Partisipan terdiri dari 8 orang Tim SIBAT Kota Surakarta dengan karakteristik yang terlihat pada tabel berikut ini :

Tabel 1.1

\begin{tabular}{lcccc}
\hline No & Partisipan & $\begin{array}{c}\text { Jenis } \\
\text { Kelamin }\end{array}$ & Usia & Pendidikan Terakhir \\
\hline 1. & P1 & Laki-laki & 37 tahun & Diploma 3 \\
2. & P2 & Laki-laki & 36 tahun & SMP \\
3. & P3 & Laki-laki & 47 tahun & SMA \\
4. & P4 & Perempuan & 48 tahun & Diploma 1 \\
5. & P5 & Perempuan & 49 tahun & SMA \\
6. & P6 & Perempuan & 44 tahun & Sarjana \\
7. & P7 & Perempuan & 50 tahun & SMA \\
8. & P8 & Perempuan & 46 tahun & SMA \\
\hline
\end{tabular}

(Sumber : Data Primer) 


\section{A. Tim Siaga Bencana Berbasis Masyarakat (SIBAT) PMI Kota Surakarta}

Tim SIBAT di PMI Kota Surakarta terbagi dalam 46 desa berjumlah 455 orang dan terdiri dari 221 laki-laki dan 234 perempuan. Namun di sentralkan menjadi 5 ketua Tim SIBAT sesuai dengan jumlah kecamatan. Keaktifan dari tim SIBAT juga mempengaruhi pengetahuan dan ketrampilan dari tiap individu.

Berdasarkan data jumlah kelurahan dan kecamatan yang terdaftar dari Kota Surakarta, data tersebut sudah sesuai karena di Kota Surakarta dengan luas 44,04 km². Kota Surakarta terdiri dari 5 kecamatan, 51 kelurahan, 604 RW dengan jumlah RT sebanyak 2.714 dan jumlah KK sebanyak 169.772 jiwa pada tahun 2021. Jumlah RW terbesar terdapat di Kecamatan Banjarsari yaitu sebanyak 176 dengan jumlah RT sebanyak 877. Jumlah RW dan RT yang paling kecil adalah Kecamatan Serengan yaitu hanya sebesar 72 dan 312. (Surakarta, 2020)

\section{B. Peran Tim SIBAT dalam Satgas Jogo Tonggo di PMI Kota Surakarta}

1. Tim SIBAT membantu masyarakat apabila masyarakat membutuhkan bantuan.

Berdasarkan hasil wawancara didapatkan bahwa Tim SIBAT memiliki peran yang cukup besar karena merupakan penggerak dan pelaksana kegiatan untuk membantu masyarakat. Hal ini terdapat dalam cuplikan wawancara berikut ini :

"Saat ini selain menjadi tim SIBAT, saya juga menjadi Satgas Jogo Tonggo. Tugas kami untuk bagaimana membantu masyarakat diwilayah kami. Ya..tidak perlu melihat apa masalahnya. Semua hal kami harus siap membantu masyarakat", P3, 25-12-2020).

Sesuai dengan kajian yang telah dilakukan bahwa Tim SIBAT bersama masyarakat melakukan pemetaan wilayah untuk mengetahui tingkat kerentanan/ kerawanan maupun pemetaan sumber daya. Selain itu membantu aparat desa/kelurahan, LPM, maupun BPD dalam merumuskan Rencana Pengendalian dan Operasional melalui pencegahan, mitigasi, dan kesiapsiagaan maupun upaya-upaya tanggap darurat bencana. (Parahita et al., 2016) 
2. Penyuluhan mengenai kesiapsiagaan bencana yaitu dalam bentuk sosialisasi kepada masyarakat dalam pencegahan COVID-19.

Wawancara lain juga menyebutkan bahwa Tim SIBAT yang menjadi Satgas Jogo Tonggo juga memberikan penyuluhan bagaimana pencegahan COVID-19. Hal ini terdapat dalam cuplikan wawancara berikut ini :

"Tugas kami ya sepenuhnya untuk kemanusiaan ya membantu penderita COVID-19 yang karantina di rumah. Membuat jadwal pemberian makan, kami juga memberikan pemahaman ke masyarakat bagaimana mencegah COVID-19. Kemarin saya membagikan paket PHBS, memberi info ke masyarakat bagaimana cara mencegah COVID19"'(P1, 24-12-2020).

Informasi pencegahan Covid-19 bakal efektif tersebar melalui relawan binaan PMI ini. Cuci tangan, jaga jarak aman, diam di rumah atau bermasker saat di luar adalah beberapa anjuran agar masyarakat terhindar dari Covid-19. Namun pesan yang sudah tersebar luas ini belum sepenuhnya diketahui masyarakat. Kelompok masyarakat tertentu memerlukan pendekatan khusus agar menyadari pentingnya anjuran tersebut (Paraswati, 2020).

3. Melaporkan kepada pihak dinas kesehatan bila ada warga yang menjadi penderita COVID-19.

"Tugas kita, satu mensosialisaikan COVID-19, melakukan spraying, menyalurkan bantuan untuk yang isolasi mandiri dan melaporkan ke dinas kesehatan bila ada penyebaran COVID-19 di lingkungan kami. Jadi kalo ada yg positif COVID-19 ya komunikasi sama bu bidan dan pak RT”, (P4, 27-12-2020).

Salah satu peran dari Satgas Jogo Tonggo adalah berkoordinasi dengan puskesmas, dinas kesehatan terkait untuk pemantauan penderita COVID-19 sesuai dengan panduan Satgas Jogo Tonggo yang dikeluarkan oleh Pemerintah Provinsi Jawa Tengah (PPID Jawa Tengah, 2020)

4. Menggalakan perilaku hidup bersih dan sehat (PHBS) di masyarakat.

Wawancara yang kami lakukan banyak pembahasan mengenai PHBS antara lain : 
“Kami sudah membagikan paket PHBS ke warga...." (P5, 26-122020).

"Untuk penderita COVID-19 yang diisolasi di rumah langsung kami beritahu bagaimana PHBS agar tidak menularkan COVID-19 ke keluarganya... “(P8, 24-12-2020).

Pola penerapan hidup bersih dan sehat merupakan bentuk dari perilaku berdasarkan kesadaran sebagai wujud dari pembelajaran agar individu bisa menolong diri sendiri baik pada masalah kesehatan ataupun ikut serta dalam mewujudkan masyarakat yang sehat di lingkungannya.

Program penerapan Perilaku Hidup Bersih dan Sehat (PHBS) adalah salah satu upaya untuk memberikan pelajaran berupa pengalaman pada individu, anggota keluarga, sekumpulan, maupun masyarakat umum. Tata cara PHBS dapat melalui media komunikasi, pemberian berita, serta adanya pendidikan agar terjadinya peningkatan pada pengetahuan, perubahan sikap, dan perilaku melalui metode pendekatan dari pimpinan, membina suasana, dan juga melakukan gerakan memampukan diri pada kelompok masyarakat misalnya disosialisasikan oleh Tim SIBAT (Dwi et al., 2020).

5. Membuat jadwal untuk pengiriman makanan untuk penderita COVID-19 yang isolasi mandiri di rumah.

"Dari pak RT kalo sudah memberitahu ada yang isolasi mandiri, kami membuat jadwal penyaluran makanan..”(P4, 27-12-2020).

"Kan untuk makanan dll sudah terjadwal dan dibantu masyarakat RW tersebut. Jadi kami berkoordinasi...” (P6, 26-12-2020).

Mendorong,memastikan dan memantau terselenggaranya protokol kesehatan melawan Covid-19 dengan benar dan efektif di wilayah RW salah satunya dengan membuat jadwal pemberian makanan untuk penderita COVID-19 yang menjalani isolasi mandiri. (Gubernur Provinsi Jawa Tengah, 2020).

6. Memberikan edukasi bagi penderita COVID-19 yang sudah dinyatakan sembuh untuk mengikuti donor plasma konvalesen. 
"Selalu saya tawari untuk yang sudah dinyatakan negative untuk melakukan donor plasma konvalesen..” (P8, 24-12-2020).

"Semua yang sudah kelaur dari karantina di Donohudan saya minta ke kelurahan dulu untuk saya minta ikut melakukan donor plasma konvalesen. Mereka menyatakan bersedia...” (P7, 20-12-2020).

Setelah penderita COVID-19 dinyatakan sembuh, Tim SIBAT memberikan edukasi untuk mau mendonorkan darah untuk donor plasma konvalesen.

\section{Faktor penyebab rendahnya minat penyintas COVID-19 untuk melakukan donor plasma konvalesen}

1. Penyintas COVID-19 tidak memahami apa maksud dari donor darah plasma konvalesen sehingga menyebabkan kekhawatiran dan ketakutan pada penyintas COVID-19 untuk melakukan donor plasma konvalesen.

2. Penyintas COVID-19 memiliki komorbid yang membuat mereka tidak memenuhi syarat untuk melaksanakan donor plasma konvalesen.

3. Penyintas COVID-19 tidak menyimpan hasil pemeriksaan swab negatif yang terakhir yang menunjukkan bahwa mereka sudah sehat serta tidak menyimpan hasil Surat Keterangan Sehat sehingga tidak memenuhi syarat untuk melakukan skrining calon pendonor plasma konvalesen.

4. Kurangnya sosialisasi kepada masyarakat mengenai Stigma COVID-19 sehingga muncul kekhawatiran oleh penyintas COVID-19 akan dikucilkan di masyarakat apabila masyarakat mengetahui bahwa mereka sudah pernah terkena COVID-19.

5. Tidak adanya koordinasi dari dinas kesehatan setempat dengan alasan bahwa data penyintas COVID-19 adalah data tertutup sebagai etika kesehatan sehingga pendekatan secara interpersonal kepada penyintas COVID-19 di wilayah lingkungan mereka tidak dapat dilakukan.

6. Kurangnya sosialisasi ke masyarakat mengenai bagaimana mekanisme pelaksanaan plasma konvalesen sehingga belum muncul kesadaran kepada masyarakat. 
7. Belum ada wadah dalam bentuk website, grup melalui medsos ataupun aplikasi untuk para penyintas COVID-19 dan orang yang membutuhkan donor plasma konvalesen.

\section{SIMPULAN}

Simpulan yang didapat dari hasil penelitian yang dilakukan adalah ada beberapa faktor yang mempengaruhi peran Tim SIBAT dalam menjaring penyintas COVID-19 antara lain: kurangnya pengetahuan anggota SIBAT mengenai teknis donor plasma konvalesen, stigma penderita COVID-19 yang masih tinggi di masyarakat serta ketidak tahuan penyintas COVID-19 mengenai manfaat dari donor plasma konvalesen.

\section{DAFTAR PUSTAKA}

